Info Artikel:

\title{
Pengembangan Buku Ajar Microteaching Bernuansa Islami dalam Meningkatkan Pendidikan Karakter Mahasiswa Calon Guru
}

\author{
Efriana Jon ${ }^{1}$, Ayu Permata Sari ${ }^{2}$ \\ ${ }^{12}$ STKIP Muhammadiyah Sungai Penuh
}

\begin{abstract}
Students are still difficult in understanding the basic skill of teaching. There is no handbook for the students to learn independently either in the class or at home. This research was a research and development. This learning media was developed by using four-D models. From the research result conducted, it was known that the microteaching textbook with Islamic nuance in improving the character education for the prospective teacher students is at an extremely valid category. Based on limited try out, it is known that the implementation is at an extremely excellent category. The lecturer and students' responses after using the microteaching textbook with Islamic Nuance shows positive results with the average response is practical. The result of observation on students' activity is at extremely active category and very valid, practical, effective to be used in college such as at STKIP Muhammadiyah Sungai Penuh.
\end{abstract}

Keywords: microteaching textbook, Islamic nuance, improving the character Institute for Counseling, Education and Therapy (IICET).

\section{PENDAHULUAN}

Pendidikan merupakan salah satu bidang yang sangat penting diprioritaskan dalam pembangunan nasional, karena memiliki tujuan untuk mewujudkan cita-cita mencerdaskan generasi bangsa. Hal ini, juga sesuai dengan ajaran agama islam yang bersifat universal dan berlaku untuk setiap masa dan semua tempat (Tim Dosen MPKPAI UNJA, 2014). Disamping pendidikan itu mencakup aspek jasmani, kemampuan berfikir dan pendidikan karakter juga sangatlah penting. Pada dasarnya, pendidikan karakter berpijak dari karakter dasar manusia yang bersumber langsung dari nilai moral universal (bersifat absolute) sebagai penjebatanan nilai-nilai agama yang disebut the golden rule (Mohammad Takdir Ilahi, 2014). Siapapun yang melakukan kegiatan pendidikan harus berusaha mengembangkan potensi diri peserta didik untuk memiliki kekuatan spiritual keagamaan melalui upaya mengimplisitkan nilai-nilai keagamaan pada setiap mata pelajaran yang diajarkan (Muhaimin, 2011). Relevansi pendidikan ditentukan oleh adanya keselarasan antara upaya pendidikan dengan tujuan yang ingin 
diraih (Bahrul dan Suhendra, 2011). Menjadi sumber belajar bagi semua siswa/mahasiswa membutuhkan penanganan yang unik dan beragam (Rudi Hartono, 2013). Untuk itu perlu adanya wadah dalam mencerdaskan generasi penerus yang mampu diingat ataupun disimpan dalam pikiran mereka salah satunya dari sumber belajar. Sumber-sumber yang digunakan sebagai bahan belajar terdapat pada bahan buku pelajaran yang sengaja disiapkan dan berkenaan dengan mata pelajaran tertentu (Sitiatava Rizema Putra, 2013). Namun, minimnya buku panduan dalam perkuliahan yang mengkaitkan antara ajaran agama dan pendidikan karakter yang sangat dibutuhkan diera sekarang ini perlu dikembangkan lebih lanjut.

Sebagai tenaga pengajar di Sekolah Tinggi Keguruan dan Ilmu Pendidikan (STKIP) Muhammadiyah sungai penuh, perlu dilakukan berbagai usaha guna meningkatkan pendidikan karakter mahasiswa karena hal ini sangat penting untuk meningkatkan nilai-nilai akhlak yang baik sebagai calon pendidik. Dalam Kebijakan Nasional Pembangunan Karakter Bangsa Tahun 2010-2025 ditegaskan bahwa karakter merupakan hasil keterpaduan empat bagian yaitu olah hati, olah pikir, olah raga, serta olah rasa dan karsa (Marzuki, 2014), yang perlu ditingkatkan pada semua Program Studi Pendidikan terutama pada mata kuliah microteaching, agar tercipta mahasiswa yang memiliki pengetahuan dan keahlian tidak hanya dalam bidang matematika saja tetapi juga dalam lingkungan alam sekitarnya dan akhlak. Akhlak adalah suatu keadaan yang melekat pada jiwa manusia (Ahmad dan M. Rohmadi, 2010). Selain itu buku di perpustakaan, laboratorium, alat peraga khususnya untuk mata pelajaran microteaching juga terbatas sehingga mengakibatkan minat mahasiswa terhadap pelajaran microteaching berkurang. Microteaching is effective method of learning to teach (Jamal Ma'mur, 2011). Ditambah lagi pengetahuan tentang karakter mahasiswa sebagai generasi penerus juga belum tertanam di jiwa mereka hal ini juga harus didukung dengan pemahaman agama yang cukup baik tentunya.

Berdasarkan observasi awal ditemukan bahwa kegiatan pembelajaran yang masih pasif, ketuntasan belajar mahasiswa masih rendah. Untuk mengatasi hal itu, berbagai upaya telah dilakukan pengajar seperti pemberikan remedial, memberi mereka tugas, dan upaya lain agar nilai microteaching mahasiswa baik atau meningkat. Namun upaya tersebut tidak membuahkan hasil yang optimal. Guru atau pendidik yang baik adalah yang mampu membawa peserta didiknya mencapai tujuan dan hasil yang baik sesuai dengan kaidah yang berlaku dalam dunia pendidikan. Komponen pengajaran ada tiga kategori utama yaitu guru atau dosen, isi atau materi pelajaran dan siswa/mahasiswa (Muhammad Ali, 2010). Jika kita tilik dari pengalaman sejarah bangsa, pendidikan karakter sebenarnya bukanlah hal baru dalam tradisi pendidikan di Indonesia. Beberapa pendidik Indonesia modern yang kita kenal seperti R.A Kartini, Ki Hadjar dewantara, Soekarno, Hatta, Tan Malaka, Moh, Natsir dan sebainya telah mencoba menerapkan semangat pendidikan karakter sebagai pembentuk kepribadian dan identitas bangsa sesuai dengan konteks dan situasi yang mereka alami (Doni Koesoema, 2010). Tetapi dimasa saat ini, Munculnya banyak kasus yang destruktif dalam konteks kebangsaan, misalnya terjadinya sentimen antar etnis, perselisihan antar suku, kasus-kasus narkoba, tawuran antar pelajar, kekerasan terhadap anak, begal di mana-mana, kasus Bullying, menunjukkan karakter kebangsaan yang lemah. Pembentukan karakter sedari dini akan menumbuhkan budaya karakter bangsa yang baik dan kunci utama dalam membangun bangsa (Dini Palupi Putri, 2018).

\section{METODE}

Sesuai dengan permasalahan yang diteliti, maka jenis penelitian yang digunakan adalah penelitian pengembangan (development research). Penelitian pengembangan ini menggunakan model pengembangan fourD (4-D) models, yaitu pendefinisian (define), perancangan (design), pengembangan (develop) dan penyebaran (disseminate) (Trianto, 2010). Penelitian dan pengembangan adalah penelitian yang digunakan untuk menghasilkan produk tertentu, dan menguji keefektifan produk tersebut (Sugiyono, 2011). Penelitian desain dan pengembangan merupakan kegiatan penelitian yang mengubah keadaan yang ada mentrasformasikan situasi untuk mendapatkan peningkatan kinerja individual, kelompok maupun organisasi (M. Rusdi, 2018). Subjek atau populasi penelitian ini adalah mahasiswa semester VI STKIP Muhammadiyah Sungai Penuh. Pemilihan PT uji coba dilakukan secara Purposif, teknik ini digunakan karena peneliti memiliki pertimbangan tertentu dalam menetapkan sampel sesuai dengan tujuan penelitian. Instrumen penelitian yang dikembangkan untuk mengumpulkan data dalam penelitian ini di analisis dengan cara sebagai berikut: Instrumen Validasi, Instrumen Praktikalitas dan Instrumen Efektivitas. 


\section{HASIL}

1. Tahap Pendefinisian (define phase)

Tahap pendefenisian dilakukan dengan melakukan analisis pada dua aspek, yakni analisis kebutuhan dan analisis mahasiswa.

2. Tahap Perancangan (design phase)

Berdasarkan hasil analisis pada tahap pendefinisian maka dirancang buku ajar microteaching bernuansa islami. Adapun langkah-langkah yang dilakukan dalam perencanaan pembuatan buku ajar adalah penentuan tujuan, pemilihan bahan, penyusunan kerangka, dan pemilihan bahan sesuai materi yang akan digunakan. Berikut gambar susunan isi buku ajar microteaching bernuansa islami:

Tabel 1. Susunan isi buku ajar microteaching bernuansa islami.

\begin{tabular}{ccl}
\hline Nomor & \multicolumn{1}{c}{ Bagian awal } \\
\hline $\mathbf{1}$ & Sampul luar & \\
$\mathbf{3}$ & Sampul dalam & \multicolumn{1}{c}{ Bagian isi } \\
$\mathbf{4}$ & Kata pengantar & \\
Bab & Daftar isi & \\
$\mathbf{1}$ & Pembelajaran microteaching bernuansa islami \\
$\mathbf{2}$ & Keterampilan mengajar bernuansa islami \\
$\mathbf{3}$ & Skenario microteaching \\
$\mathbf{4}$ & Pendidikan karakter \\
$\mathbf{5}$ & Metode dan media pembelajaran \\
$\mathbf{6}$ & Evaluasi pembelajaran & Bagian akhir \\
Nomor & Glosarium & \\
$\mathbf{1}$ & Daftar pustaka & \\
\hline
\end{tabular}
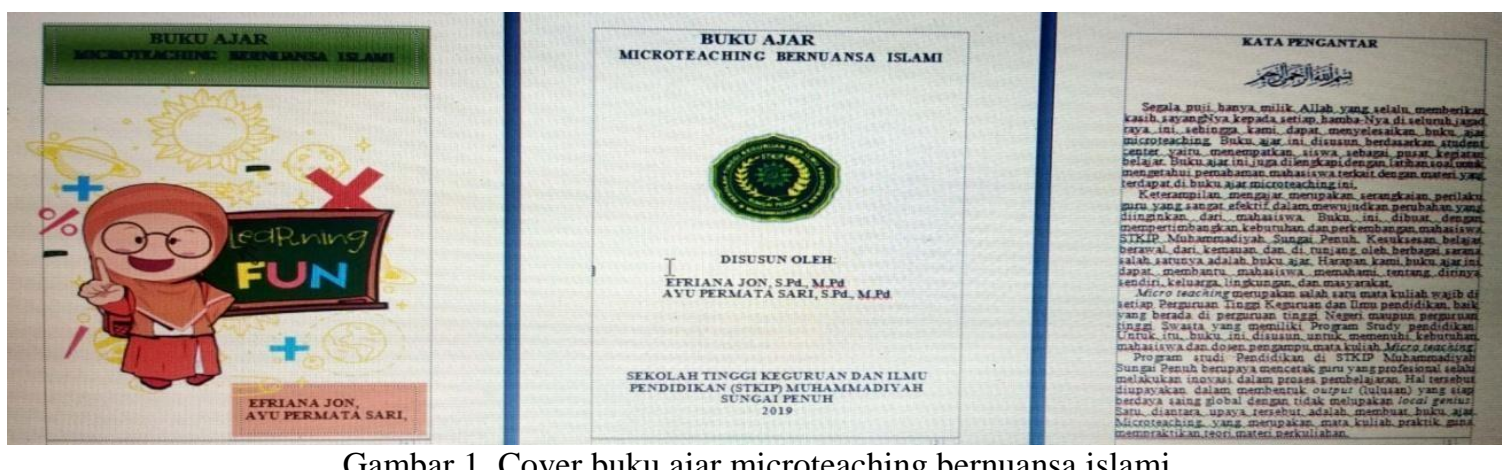

Gambar 1. Cover buku ajar microteaching bernuansa islami.

\section{Tahap Pengembangan (develop phase)}

Tahap pengembangan bertujuan untuk menghasilkan buku ajar microteaching bernuansa islami yang valid, praktis dan efektif. Oleh karena itu, pada tahap ini dilakukan mengujian validitas, praktikalitas dan efektifitas buku ajar microteaching bernuansa islami yang dikembangkan. Pengujian validitas yaitu dengan memvalidasi perangkat oleh para pakar dan praktisi, kemudian dilakukan revisi. Pengujian praktikalitas dan efektivitas yaitu dengan mengujicobakan perangkat pembelajaran yang telah dikembangkan tersebut ke dalam proses pembelajaran di kelas. Sehingga dapat terlihat dalam proses belajar mengajar, mahasiswa tidak hanya berinteraksi dengan dosen sebagai salah satu sumber belajar, tetapi memungkinkan untuk berinteraksi dengan keseluruhan sumber belajar yang dipakai untuk mencapai tujuan pembelajaran yang diinginkan terutama dengan tersedianya buku ajar microteachimg bernuansa islami. 
Tabel 2. Hasil Validasi Buku Ajar Microteaching Bernuansa Islami

\begin{tabular}{|c|c|c|c|}
\hline No. & Aspek yang dinilai & Jumlah skor validator & Kategori \\
\hline 1. & Kelayakan Isi & 4 & Sangat Valid \\
\hline 2. & Kelayakan Penyajian. & 3.6 & Sangat Valid \\
\hline 3. & Kelayakan Bahasa & 3.5 & Sangat Valid \\
\hline 4. & Kelayakan Kegrafikaan. & 3.6 & Sangat Valid \\
\hline 5. & $\begin{array}{l}\text { Keterpaduan materi microteaching yang bernuansa } \\
\text { islami. }\end{array}$ & 3.5 & Sangat Valid \\
\hline 6. & Penyajian materi sesuai dengan tujuan & 3.5 & Sangat Valid \\
\hline 7. & $\begin{array}{l}\text { pembelajaran (pendidikan karakter). } \\
\text { Desain tampilan sederhana tetapi menarik }\end{array}$ & 3.6 & Sangat Valid \\
\hline 8. & $\begin{array}{l}\text { Buku ajar sistematis dan menggunakan warna- } \\
\text { warna menarik. }\end{array}$ & 3.6 & Sangat Valid \\
\hline & Rata-rata & 3.61 & Sangat Valid \\
\hline
\end{tabular}

Berdasarkan hasil penilaian validator yang ditampilkan pada Tabel 2 dapat di lihat rata-rata skor penilaian ketiga validator terhadap buku ajar microteaching bernuansa islami adalah 3.61 dengan kategori sangat valid. Dari hasil tersebut dapat disimpulkan bahwa semua validator menyatakan bahwa buku ajar microteaching bernuansa islami yang penulis kembangkan sudah dalam kategori sangat valid.

4. Tahap Penyebaran (Dissemination phase)

Tujuan tahap penyebaran dilakukan guna melihat kepraktisan dan keefektifan dari buku ajar microteaching bernuansa islami sebagai landasan untuk meningkatkan pendidikan karakter mahasiswa calon guru di STKIP Muhammadiyah Sungai Penuh. Dengan melakukan tes dan memperoleh hasil belajar kognitif mahasiswa memperoleh rata-rata kelas 80,70 artinya mampu meningkatkan hasil belajar mahasiswa.

\section{PEMBAHASAN}

Menurut Barinto (2012) bahwa untuk mencapai keberhasilan pendidikan dan meningkatkan mutu pendidikan, guru harus memiliki kompetensi yang memadai. Hal ini tentunya didukung dengan adanya buku ajar microteaching bernuansa islami yang memadai dan memfasilitasi mahasiswa agar bisa belajar mandiri hal ini tentunya berkaitan dengan perkembangan paradigma pendidikan,dari padangan behabiorsme andangan konstruktivisme perlu perubahan guru dari memindahkan informasi kea rah pemberian pengalaman dan pengembangan berpikir (kognisi), sehingga peran guru atau dosen dari member/mengajar menjadi fasilitator yang memfasilitasi siswa agar mampu belajar secara mandiri (Subanji dan Iskandar, 2010). Untuk itu perlu adanya proses belajar, belajar merupakan proses yang diarahkan kepada tujuan, proses berbuat melalui berbagai pengalaman. Belajar juga dapat diartikan mengalami proses melihat, mengamati, memahami sesuatu sehingga seseorang itu menjadi paham. Dengan kata lain belajar adalah terjadinya perubahan mental pada diri siswa (Dimyati dan Mudjiyono, 2013). Untuk belajar lebih maksimal maka peran sumber belajar sangatlah penting salah satunya dengan telah dihasilkannya buku ajar microteaching bernuansa islami dari hasil penelitian pengembangan ini untuk meningkatkan karakter mahasiswa calon guru.

Definisi mengenai buku menurut Ensiklopedia Indonesia (dalam Sitepu, 2012) ialah "Buku mencakup semua tulisan dan gambar yang ditulis dan dilukis atas segala macam lembaran papirus, lontar, perkamen, dan kertas dengan segala bentuknya: berupa gulungan, dilubangi, dan dilihat atau dijilid muka dan belakangnya dengan kulit, kain, karton, dan kayu”. Selain itu, dalam Permendiknas Nomor 2 Tahun 2008 Pasal 1(dalam Muslich, 2010) menjelaskan bahwa "Buku teks adalah buku acuan wajib untuk digunakan di satuan pendidikan dasar dan menengah atau perguruan tinggi yang memuat materi pembelajaran dalam rangka peningkatan keimanan, ketakwaan, akhlak mulia, dan kepribadian, penguasaan ilmu pengetahuan dan teknologi, peningkatan kepekaan dan kemampuan estetis, peningkatan kemampuan kinestetis dan kesehatan yang disusun berdasarkan standar nasional pendidikan”.

Buku ajar adalah buku pegangan untuk suatu matakuliah yang ditulis dan disusun oleh pakar bidang terkait dan memenuhi kaidah buku teks serta diterbitkan secara resmi dan disebar luaskan (Fitri, 2012: 5). Menurut Febri Cahyo (2012: 2), buku ajar dianggap sebagai sarana penunjang bagi penerapan kurikulum, buku 
ajar merupakan sarana belajar yang digunakan untuk menunjang suatu program pembelajaran. Lebih terperinci lagi Bacon dalam Putrajunio (2014: 3), mengemukakan bahwa "buku teks (ajar) buku yang dirancang buat penggunaan di kelas, dengan cermat disusun dan disiapkan oleh para pakar atau ahli dalam bidang itu dan dilengkapi dengan sarana-sarana pengajaran yang sesuai dan serasi”. Buku ajar adalah jenis buku yang digunakan dalam aktivitas belajar dan mengajar. Prinsipnya semua buku dapat digunakan untuk bahan kajian pembelajaran. Buku ajar disusun dengan alur dan logika sesuai dengan rencana pembelajaran. Buku ajar disusun sesuai kebutuhan belajar siswa atau mahasiswa. Buku ajar disusun untuk mencapai tujuan pembelajaran atau kompetensi tertentu. Penulisan buku ajar harus mengacu kepada kurikulum dan harus tercermin adanya bahan yang tingkat kedalaman dan keluasannya berbeda antara kelas (Putrajunio, 2014: 5). Menurut Suharjono ( 2011 : 5), buku ajar adalah buku yang digunakan sebagai buku pelajaran dalam bidang studi tertentu, yang merupakan buku standar yang disusun oleh pakar dalam bidangnya untuk maksud-maksud dan tujuan instruk- sional, yang dilengkapi dengan sarana-sarana pengajaran yang serasi dan mudah dipahami oleh para pemakainya di sekolahsekolah dan perguruan tinggi sehingga dapat menunjang suatu progam pengajaran.

Adapun standar-standar untuk menentukan kualitas buku teks pelajaran (Tarigan, 2009) yaitu: sudut pandang, kejelasan konsep, relevansi kurikulum, menarik minat, menumbuhkan motivasi, menstimulasi aktivitas siswa, ilustratif, komunikatif, menunjang mata pelajaran lain, menghargai perbedaan individu, dan memantapkan nilai-nilai. microteaching adalah sebuah pembelajaran dengan salah satu pendekatan atau cara untuk melatih penampilan mengajar yang dilakukan secara "micro" atau disederhanakan. Penyederhanaan disini terkait dengan setiap komponen pembelajaran, misalnya dari segi waktu, materi, jumlah siswa, jenis keterampilan dasar mengajar yang dilatih, penggunaan metode dan media pembelajaran, dan unsur-unsur pembelajaran lainnya (Sukirman, 2012). Hamalik juga mengatakan bahwa pengajaran mikro merupakan teknik baru dan menjadi bagian dalam pembaruan. Penggunaan pengajaran mikro dalam rangka mengembangkan keterampilan mengajar calon guru atau sebagai usaha peningkatan, adalah suatu cara baru terutama dalam sistem pendidikan guru di negera kita (Hamalik, 2009). Delapan keterampilan dasar mengajar tersebut adalah 1) keterampilan membuka dan menutup pembelajaran, 2) keterampilan menjelaskan, 3) keterampilan bertanya (dasar, lanjut), 4) keterampilan mengadakan variasi, 5) keterampilan memberikan penguatan, 6) keterampilan mengelola kelas, 7) keterampilan membelajarkan kelompok kecil dan perorangan, 8) keterampilan memimpin diskusi kelompok kecil (Helmiati, 2013).

Dalam Kamus Bahasa Indonesia kata "karakter" diartikan dengan tabiat, sifat-sifat kejiwaan, akhlak atau budi pekerti yang membedakan seseorang dengan yang lain, dan watak. Karakter juga bisa berarti huruf, angka, ruang, simbul khusus yang dapat dimunculkan pada layar dengan papan ketik (Pusat Bahasa Depdiknas, 2009). Dalam Al-Qur'an dan hadis dijelaskan bahwa sesungguhnya dalam ilmu pengetahuan agama terdapat petunjukpetunjuk mengenai berbagai kehidupan manusia yang tampak amat ideal dan agung. Islam mengajarkan kehidupan yang dinamis dan progresif, menghargai akal pikiran melalui perkembangan ilmu pengetahuan dan teknologi, bersikap seimbang dalam memenuhi kebutuhan material dan spiritual, senantiasa mengembangkan kepedulian sosial, menghargai waktu, bersikap terbuka, demokratis, berorientasi pada pada kualitas, egaliter, kemitraan, feodalistik, mencintai kebersihan, mengutamakan persaudaraan, berakhlak mulia dan sikap-sikap positif lainnya (Fadhil, 2010). Pendidikan karakter menurut Ratna Megawangi (2004), sebuah usaha untuk mendidik anak-anak agar dapat mengambil keputusan dengan bijak dan mempraktekkannya dalam kehidupan sehari-hari sehingga dia dapat memberikan kontribusi yang positif bagi lingkungannya. Sebuah transformasi nilai-nilai kehidupan untuk ditumbuhkembangkan dalam kepribadian seseorang sehingga menjadi satu dalam perilaku kehidupan orang itu (Fakry Gaffar, 2010).

Sebagai seorang dosen harus mampu memfasilitasi mahasiswa dengan berbagai sumber belajar yang layak. Karena guru berperan sebagai manager of learning yang berarti guru sangat menentukan dalam hal perencanaan, pelaksanaan dan penilaian produktivitas proses belajar mengajar (Widodo, 2011). Hasil penelitian Rusilowati dkk (2012) menyatakan bahwa Better teaching learning berkarakter dapat membekali kompetensi pedagogi mahasiswa calon guru serta dapat menumbuhkan karakter mahasiswa. Dalam membentuk karakter guru yang berkompetensi tinggi, melalui pembelajaran mikro calon guru harus diberikan bekal sejak dini agar ketika berada dilapangan, guru bisa secara luwes menghadapi berbagai kendala dilapangan (Zunaidah, 2016). Bagi dunia Perguruan Tinggi justru harus menjadi pemacu dan pemicu bagi upaya mempelajari dan mendalami islam. Keharusan ini merupakan tuntutan mengingat mahasiswa dan pascamahasiswa dalam skala yang bervariasi sebagai agent social of change di tengah bangsa Indonesia yang mayoritas beragama Islam, untuk itu buku ajar microteaching bernuansa islami sangatlah dibutuhkan saat ini (Ali Anwar Yusuf, 2003). 


\section{KESIMPULAN}

Pada tahap pengembangan buku ajar microteaching bernuansa islami divalidasi oleh 3 validator dan memperoleh hasil 3,61 dengan kategori sangat valid. Praktikalitas hasil data pengamatan terhadap keterlaksanaan dan keterpakaian buku ajar microteaching bernuansa islami dalam proses pembelajaran memperoleh nilai 3,57 dengan kategori sangat praktis. Hasil analisis respon dosen terhadap buku ajar microteaching bernuansa islami memperoleh skor 3,51 kategori sangat praktis. Hasil analisis respon mahasiswa memperoleh skor 3,51 dengan kategori juga sangat praktis. Efektivitas dilihat dari aktivitas mahasiswa memperoleh nilai rata-rata 84,39 kategori sangat tinggi. Hasil rekapitulasi nilai afektif mahasiswa rata-rata 97,58 dengan criteria sangat baik. Hasil untuk psikomotor mahasiswa rata-rata 96,72 kriteria sangat baik. Hasil belajar kognitif mahasiswa memperoleh rata-rata kelas 80,70 artinya mampu meningkatkan hasil belajar mahasiswa.

\section{REFERENSI}

Ali Idrus dan Rasimin. 2010. Pengembangan Profesi Guru. Jakarta: Gaung Persada.

Ahmad Taufik dan M. 2010. Rohmadi Pendidikan Karakter Berbasis Agama. Surakarta:Yuma Pressindo.

Bahrul Hayat dan Suhendra Yusuf. 2011. Benchmark Internasional Mutu Pendidikan. Jakarta:Bumi Aksara.

Barinto. 2012. Hubungan Kompetensi Guru dan Supervisi Akademik denga Kinerja Guru SMP Negeri SeKecamatan Percut Sei Tuan. Jurnal Tabularasa PPS Universitas Medan. From: http://digilib.unimed.ac.id/public/UNIMED-article-23935-barinto.pdf.

Doni Koesoema. 2010. Pendidikan Karakter: strategi mendidik anak di zaman global. Jakarta: grasindo.

Dimyati dan Mudjiyono. 2013. Belajar dan Pembelajaran. Jakarta: Renika Cipta.

Fitri. 2012. Perbedaan Buku Teks dan Buku Ajar. From:http://www.kopertis12.or.id/2012/09/22/perbedaanbuku-teks-buku-ajar-dan-buku diktat\%E2\%80\%8F.

Febri Cahyo. 2012. Pedoman Penulisan Buku Ajar. from:https://id.scribd.com/doc/88441861/PedomanPenulisan-Buku-Ajar.

Fadhil Al-Jamali. 2010. Menerebas Krisis Pendidikan Dunia Islam (Terj.)H.M.Rasyidi (Jakarta: Golden Terayon Press.

Helmiati. 2014. Micro Teaching Melatih Keterampilan Dasar Mengajar. Yogyakarta: Aswaja Pressindo.

Jamal Ma'mur Asmani. 2011. Pengenalan dan Pelaksanaan Lengkap Microteaching dan Team Teaching. Yogyakarta: Diva Press.

Muhammad Ali. 2010. Guru dalam Proses belajar mengajar. Bandung:Sinar Baru Algensindo.

Muhammad Takdir Ilahi. 2014. Gagalnya Pendidikan Karakter analisis dan solusi pengendalian Karakter Emas Anak Dididk. Jogjakarta:Ar-Ruzz

M. Rusdi. 2018. Penelitian Desain dan Pengembangan Kependidikan. Depok:Raja Wali Press

Marzuki. 2019. Pendidikan Karakter Islam. Jakarta: Raja Walipress.

Muslich Mansur. 2010. Text Book Writing: Dasar-dasar Pemahaman, penulisan dan pemakaian Buku Teks. Jogjakarta: Ar-Ruzz Media.

Putrajunio. 2014. Pengertian Buku Ajar, Buku Teks Dan Buku Diktat. from: http://putrajunio.blogspot.co.id/2014/06/pengertian-buku-ajar- buku-teks-dan-buku.html.

Rusilowati, A., Hartono, Supriyadi. 2012. Pengembangan Model Pembelajaran Better Teaching Learning Berkarakter untuk Membekali Kompetensi Pedagogi Mahasiswa Calon Guru. Jurnal Penelitian Pendidikan. Vol.29 No.2. Semarang: LP@M Unnes.

Rudi Hartono. 2013. Ragam Model Mengajar yang muda diterima Murid. Jogjakarta:Diva Press

Fakry Gaffar. 2010. Pendidikan Karakter Berbasis Islam. (disampaikan Pada Workshop Pendidikan Karakter Berbasis Agama). Yogyakarta.

Sitepu, B.P. 2012. Penulisan Buku Teks Pelajaran. Bandung: PT Remaja Rosdakarya.

Sitiatara Rizema Putra. 2013. Desain Belajar Mengajar Kreatif Berbasisi Sain. Jogjakarta:Diva Press

Sukirman Dadang. 2012. Pembelajaran Micro Teaching. Jakarta: Direktorat Jenderal Pendidikan

Subanji dan Iskandar.2010. Meningkatkan Profesionalisme Guru Sekolah Dasar Melalui Teachers Quality Improvement Program (TEQIP) Berbasis Lesson Study. Jurnal TEQIP (1). from: http://teqip.com/download/jteqip/jurnal-1-11.pdf.

Suharjono. 2011. Definisi Buku Ajar. from:digilib.unila.ac.id/1765/8/BAB\%20II.pdf.

Sugiyono. 2011. Metode Penelitian Kuantitatif Kualitatif R\&D. Jakarta: Alfabeta

Sukmadinata, Nanasyaodih. 2009. Metode Penelitian dan Pendidikan. Bandung: PT Remaja Rosdakarya.

Trianto. 2010 . Mendesain Model Pembelajaran Inofatif-Progresif. Jakarta: Bumi Aksara. 
Tarigan, Henry Guntur dan Djago Tarigan. 2009. Telaah Buku Teks Bahasa Indonesia. Bandung Angkasa. Tim Dosen MPK-PAI Universitas Negeri Jambi. 2014. Pendidikan Agama Islam Berbasis Karakter. Jakarta: Referensi (gaung Persada Press Group).

Widodo A,. 2011. Peningkatan Kemampuan mengajar Guru-guru SD melalui Lesson Study. Artikel. From: http:/jurnal.upi.edu/file/jurnal_Aril.pdf.

Zunaidah. 2016. Meningkatkan Kompetensi Calon Guru melalui Kegiatan Microteaching berbasis Lesson Study (LS) Mahasiswa Pendidikan Biologi. Jurnal Efektor. 